\title{
CARACTERIZAÇÃO DA PRODUÇÃO E QUALIDADE DO LEITE EM PROPRIEDADES DE AGRICULTURA FAMILIAR NA REGIÃO SUL DO RIO GRANDE DO SUL
}

\section{Characterization of milk production and quality on family farming properties in the southern region of Rio Grande do Sul}

\author{
Bárbara Ponzilacqua Silva ${ }^{l}$, Amanda Krummenauer ${ }^{l}$, \\ Luiz Filipe Damé Schuch ${ }^{1}$, João Luiz Zani ${ }^{{ }^{*}}$
}

\section{RESUMO}

A cadeia leiteira possui grande importância socioeconômica no cenário agrícola nacional. Agricultores familiares possuem expressiva importância neste contexto, representando $60 \%$ desta produção. Neste trabalho, objetivou-se analisar o perfil das Unidades de Produção de Leite (UPLs) de agricultura familiar na Região Sul do Rio Grande do Sul. Para isto, foram aplicados questionários a 54 agricultores familiares de uma cooperativa do município de Canguçu, e analisadas amostras de leite dos tanques resfriadores, traçando perfis de produção, dos proprietários, parâmetros de qualidade do leite, higiene do processo, condições e tipo de ordenha. Os resultados foram comparados com os padrões estabelecidos pela Instrução Normativa $\mathrm{n}^{\mathrm{o}} 76$ de 2018. Os produtores possuem baixa escolaridade, entretanto, 70,4\% recebem algum tipo de assistência técnica. A área média das propriedades é de 18,4 hectares. A maioria das UPLs estudadas possuem outras atividades agrícolas como uma forma de incrementar a renda das famílias. A produção possui baixa tecnificação, pois a ordenha manual é realizada em 59,2\% das UPLs analisadas. Em 50\% das UPLs (27), os padrões de Contagem Bacteriana Total (CBT) acima do permitido pela legislação refletiram falhas de manejo e de boas práticas de ordenha, pois não são práticas comuns pré e pós dipping, secagem com papel toalha e identificação de mastites clínicas ou subclínicas. As análises de Contagem de Células Somáticas (CCS) e das médias dos constituintes do leite

1 Universidade Federal de Pelotas, Laboratório de Bacteriologia e Saúde Populacional, Rua Gomes Carneiro, 01, Centro, 96010-610, Pelotas, RS, Brasil. E-mail: jluizzani@outlook.com

* Autor para correspondência 
como gordura, lactose, proteínas e teor de sólidos se mantiveram dentro dos padrões estabelecidos pela legislação.

Palavras chave: Contagem Bacteriana Total; Instrução Normativa $n^{\circ} 76$; boas práticas de ordenha.

\begin{abstract}
The dairy chain has great socioeconomic importance in the national agricultural scenario. Family farmers have significant importance in this context, representing $60 \%$ of this production. The objective of this study was to analyze the profile of Family Farming Milk Production Units (UPLs) in the Southern Region of Rio Grande do Sul. For this purpose, questionnaires were applied to 54 family farmers from a cooperative in the municipality of Canguçu, and milk samples from the cooling tanks were analyzed, tracing production and farmers profiles, milk quality parameters, hygiene of the process, conditions and type of milking. The results were compared with the standards established by Normative Instruction $\mathrm{n}^{\circ}$. 76. The producers have low levels of education, however, $70.4 \%$ receive some type of technical assistance. The average area of the properties is 18.4 hectares. Most of the UPLs studied have other agricultural activities to increase household income. The production has low technification, as manual milking is performed in $59.2 \%$ of the analyzed UPLs. Total Bacterial Count patterns, which weren't in accordance with legislation, reflected management failures and lack of better milking practices, since pre and post dipping practices were not common, paper towel drying, and clinical or subclinical mastitis identification. The analysis of Somatic Cell Count (CCS) and the averages of milk constituents such as fat, lactose, proteins and solids content remained within the standards established by legislation.
\end{abstract}

Keywords: Total Bacterial Count; Normative Instruction $n^{\circ} .76$; good milking practices.

\section{INTRODUÇ̃̃̃O}

O leite é um dos produtos de origem animal mais consumidos no mundo e possui grande importância socioeconômica no cenário agrícola nacional e, em especial, para um expressivo número de agricultores familiares, em virtude de serem responsáveis por $60 \%$ da produção de leite no Brasil. No ano de 2017 , estima-se que a quantia de leite produzido no Brasil foi de 30,11 bilhões de litros. O estado do Rio Grande do Sul é o segundo em participação nacional desta produção, com $13,28 \%$, representando aproximadamente 4 bilhões de litros (IBGE, 2017).
A legislação brasileira, representada pela Instrução Normativa $\mathrm{n}^{\circ} 76$ (IN 76), de 26 de novembro de 2018, do Ministério da Agricultura, Pecuária e Abastecimento (MAPA), estabelece requisitos mínimos de qualidade na produção de leite, regularizando e padronizando a produção. Além das características físico-químicas, são citados na IN 76 os padrões quantitativos de qualidade do leite: Contagem de Células Somáticas (CCS) e Contagem Bacteriana Total (CBT) (BRASIL, 2018).

Por meio dos níveis de CBT e CCS é possível detectar falhas na higiene da ordenha (MILLOGO et al., 2010) e no manejo dos 
animais (LANGONI et al., 2011). Estas falhas podem estar relacionadas à baixa informação que os produtores têm sobre as boas práticas no processo produtivo (ROSA; QUEIROZ, 2007) e a falta de assistência técnica. Em um estudo da EMATER (RIES, 2017), 25,9\% dos produtores gaúchos entrevistados relataram possuir deficiências na qualidade do leite, dificultando sua produção e comercialização.

É necessária uma análise permanente do sistema de produção dos rebanhos, principalmente em pequenas propriedades, não só por sua relevância na produção mas também social, de modo que estas informações possam servir como subsídio para a tomada de decisões adequadas às realidades sociais e econômicas locais (LOPES et al., 2010).

Com o intuito de estudar características da produção leiteira e verificar a adequação aos padrões de qualidade estabelecidos na IN 76 foram analisadas Unidades de Produção de Leite (UPLs) de uma cooperativa localizada no município de Canguçu, na região sul do estado do Rio Grande do Sul, município também conhecido como a capital nacional da agricultura familiar (FERNANDES; WOODHOUSE, 2008).

\section{MATERIAL E MÉTODOS}

O trabalho foi realizado junto a uma cooperativa no município de Canguçu, localizado na Serra dos Tapes ao sul do estado do Rio Grande do Sul. Das 220 UPLs da região, 1 a cada 4 foi selecionada via amostragem sistemática, acompanhando as diferentes rotas de coleta de leite realizadas pelos caminhões tanque.

Para um diagnóstico das propriedades, foram aplicados questionários a fim de averiguar a realidade da região no que tange o atendimento às exigências descritas na IN 76 . As perguntas foram dirigidas ao proprietário, relacionando suas características pessoais, assim como da propriedade e condições de produção, como o processamento da ordenha, higiene, equipamentos e manejo dos animais.

Além disto, foi realizada a coleta de uma amostra de leite refrigerado, para as análises de CCS, CBT e composição, e encaminhadas ao Laboratório de Referência de Qualidade do Leite da EMBRAPA Clima Temperado para análise em equipamento automático de citometria de fluxo. Os componentes do leite, tais como lactose, gorduras totais, proteínas e sólidos totais, foram quantificados através de espectrofotometria com infravermelho.

Os dados foram compilados e armazenados em planilhas do software Microsoft Excel ${ }^{\circledR}$, onde foram analisados estatisticamente por meio do software Bioestat 5.3.

\section{RESULTADOS E DISCUSSÃO}

Com relação ao nível de escolaridade dos produtores, cerca de $90,7 \%$ dos entrevistados relataram não terem concluído o ensino fundamental, e apenas $1,8 \%$ possuía o ensino médio completo. $\mathrm{O}$ baixo grau de instrução dos produtores gera impactos na produção leiteira, podendo refletir em dificuldade de entender e de se adequar às legislações existentes e de produzir um leite de boa qualidade (PICOLI et al., 2015; SCALCO; SOUZA, 2006). Além disso, pode influenciar na tomada de decisões e na interpretação de laudos técnicos. Dentre os produtores avaliados, 70,4\% recebem algum tipo de assistência técnica pelo menos uma vez por ano, não necessariamente na área de produção leiteira.

A área média das 54 UPLs estudadas foi de 18,4 hectares (ha), sendo que 51,8\% delas possuem menos de 20 hectares. Este dado é semelhante à área média das propriedades gaúchas que, segundo levantamento realizado pela EMATER (RIES, 2017), é de 19,1 ha. O módulo fiscal no município é de 16 ha (INCRA, 2013).

Foi identificado que apenas uma das 
propriedades estudadas não possuía outras atividades concomitantes à produção de leite. As atividades mais frequentes foram a produção de milho, fumo e soja com 92,$6 ; 57,4$; $22,2 \%$ das propriedades, respectivamente. Segundo Schneider (2003), é característica na região sul do estado do Rio Grande do Sul a mão de obra familiar, e a produção de leite é um complemento às demais atividades realizadas na pequena propriedade. Além disto, a produção de grãos como o milho, muitas vezes é realizada com a finalidade de alimentar os animais.

A pluralidade de atividades agrícolas no contexto de pequenas produções pode ser uma alternativa para que as famílias aumentem a renda. No entanto, Picoli et al. (2014) observaram que nas UPLs em que a atividade leiteira era exclusiva, os índices produtivos foram melhores do que naquelas onde a atividade não era única.

Para Milinski et al. (2008) grande parcela do leite produzido no território nacional é proveniente de um elevado número de pequenas propriedades pouco ou nada especializadas, e com pequeno volume de produção diária. A Tabela 1 apresenta a produção média diária das propriedades estudadas, em uma ou duas ordenhas por dia.

A análise por extrato de produção permite revelar a importância de estabelecimentos com escala de produção abaixo de 100 litros diários, como é o caso da maioria das propriedades analisadas(MAIA et al., 2013). Dentre as 54 UPLs, observou-se grande oscilação dos índices. O número de vacas em lactação variou entre 1 e 18 , com uma média de 5,27 animais por propriedade, e o rendimento médio foi de 7,25 litros de leite por vaca, por dia. Este valor supera a média nacional, que é de 5,37 litros/vaca/dia, porém, é inferior à média da região Sul que é de 8,99 litros/vaca/dia (IBGE, 2017).

O tipo de ordenha tem fundamental importância na exploração do leite, afetando diretamente a produtividade e qualidade (DINGWELL et al., 2004). A análise dos dados revelou que a ordenha manual ainda é predominante nessa região, pois é realizada em 59,2\% das UPLs, enquanto, $40,8 \%$ possuem ordenha mecanizada. Das propriedades com ordenha mecanizada, todas utilizam o sistema balde ao pé, e possuem uma produção média de $63,9 \mathrm{~L} /$ dia, enquanto que as que realizam ordenha manual tem a produção média cerca de 3 vezes menor, com 18,5 L/dia. Esta diferença em produtividade pode ser atribuída à facilidade de manejo da ordenha mecanizada, porém nenhum tipo de ordenha exime cuidados de higiene com o ambiente, equipamentos utilizados e com o próprio animal. Estes dados evidenciam a baixa tecnificação das UPLs na região alvo do estudo.

Quando avaliadas as práticas de manejo e higiene, observou-se que $59,3 \%$ das

Tabela 1 - Média de produção diária de leite das propriedades avaliadas na região de Canguçu, RS

\begin{tabular}{ccc}
$\begin{array}{c}\text { Média de litros produzidos } \\
\text { por dia }\end{array}$ & $\begin{array}{c}\text { Número de propriedades } \\
\text { (unidade) }\end{array}$ & $\begin{array}{c}\text { Percentual das } \\
\text { propriedades }\end{array}$ \\
\hline Até 30L & 26 & $48 \%$ \\
30 a 50L & 15 & $28 \%$ \\
50 a 100L & 12 & $22,2 \%$ \\
Acima 100L & 1 & $1,8 \%$ \\
\hline
\end{tabular}


propriedades utilizam ordenha manual realizada em grande parte em locais com piso de terra, e as restantes, que utilizam a ordenha mecanizada, a fazem principalmente em locais com o piso de cimento. Também foi observado que os locais onde é feita a ordenha mecanizada são mais varridos antes da ordenha que os locais onde é feita a ordenha manual, mas somente $31,8 \%$ realizam a lavagem diária do piso da sala de ordenha no sistema mecanizado.

A falta de manutenção do equipamento de ordenha também pode influenciar na qualidade do leite. Vilar et al. (2012) afirmam que a introdução de novos patógenos no úbere pode acontecer pela ausência da manutenção, tornando essa etapa crítica no controle da mastite. Dos 22 produtores que utilizam ordenha mecanizada, a porcentagem dos que realizam manutenção em seus equipamentos pelo menos uma vez ao ano é de $45,4 \%$, enquanto a frequência recomendada pelos mesmos autores, é semestral.

A higienização adequada das mangueiras e teteiras também é um ponto crítico (VILAR et al., 2012). Dentre as 22 propriedades que possuem a ordenha mecanizada, 4 não realizam limpeza periódica nos equipamentos, enquanto $59,1 \%$ limpam as mangueiras e teteiras com detergente alcalino e detergente ácido. Após a ordenha é recomendado que o equipamento seja lavado com a solução detergente alcalino clorada para a remoção de gorduras e proteínas, e pelo menos uma vez na semana é indicado o uso do detergente ácido para a remoção de depósitos minerais provenientes da água e do leite (MARTINS et al., 2012). Vilar et al.(2008) encontraram resultados significativos de presença de microrganismos para propriedades com sistema balde ao pé devido ao sistema de lavagem ser manual, revelando uma dificuldade na higienização do equipamento. Os dados obtidos neste estudo demonstram que os produtores não têm conhecimento adequado do processo de manutenção do equipamento de ordenha e nem da melhor forma de higienização.

Quando questionados sobre os procedimentos de higiene pré-ordenha, 96,3\% dos produtores afirmaram lavar os tetos das vacas com água corrente. O pré-dipping não era realizado por $92,6 \%$ dos produtores. Esta técnica é realizada com o uso de antissépticos, objetivando eliminar bactérias que estejam presentes na superfície do teto antes que o tampão de queratina que protege o canal do teto se rompa. A secagem era realizada com pano coletivo em 59,2\% das UPLs. O uso do pano coletivo permite a transferência de microrganismos entre os tetos dos animais, contribuindo para sua disseminação, sendo assim, é recomendada a realização de prédipping e secagem individual de cada teto com papel descartável (MOLINA, 2008).

A ausência de boas práticas de ordenha promove a redução da qualidade do leite, além de influenciar no desenvolvimento de novos casos de mastite. A prática do pósdipping é associada à redução de infecções intramamárias ambientais devido ao seu caráter de proteção do canal do teto após a ejeção do leite, uma vez que ele permanece aberto por um longo período (PONZILACQUA et al., 2013). Das 54 propriedades estudadas, $87,0 \%$ não realizam pós-dipping.

Um procedimento que contribui para a não contaminação dos tetos é manter as vacas em pé após a ordenha, escolhendo este momento para alimentá-las, para que não deitem enquanto o esfíncter do teto ainda está aberto (TEODORO et al., 2013). Apenas $14,8 \%$ das propriedades visitadas optavam por realizar a alimentação dos animais após a ordenha, enquanto $61,1 \%$ realizavam a alimentação durante a ordenha, o que estimula o trato gastrointestinal e pode iniciar a expulsão das fezes, aumentando assim a contaminação do local da ordenha.

A mastite é a doença mais associada a gastos expressivos com o rebanho leiteiro (HOGEVEEN et al., 2011). Além de reduzir 
a produtividade do rebanho, influencia na qualidade de leite que é produzido. Alguns estudos demonstram que a mastite subclínica, aquela que não demonstra indício de infecção no animal, pode resultar numa perda média de até 78 euros por vaca no rebanho ao ano (HAGNESTAM-NIELSEN; ØSTERGAARD, 2009). Das 54 propriedades estudadas $32(59,2 \%)$ não realizam nenhum tipo de diagnóstico para mastite.

O teste da caneca de fundo preto é indicado para a identificação de mastite clínica e deve ser realizado diariamente (MARTINS et al., 2012). Apesar de 72,2\% dos produtores deste estudo descartarem os primeiros jatos de leite antes de iniciar a ordenha, apenas $12,9 \%$ realizavam este teste. Dados semelhantes foram encontrados por Bozo et al. (2013) a contagem bacteriana total (CBT) em propriedades de leite no estado do Paraná. Os autores afirmaram que quando estabelecidos padrões de boas práticas de ordenha, manutenção e higienização dos equipamentos os valores de CBT e CCS foram reduzidos.

Outro teste indicado para analisar a presença de mastite no rebanho, na forma subclínica, para tratamento precoce e prevenção é o California Matits Test (CMT). Seu uso é recomendado sempre que houver suspeita da mastite ou pelo menos uma vez ao mês (MARTINS et al., 2012). Apenas 29,6\% dos produtores estudados faziam o uso do CMT mensalmente ou quando suspeitavam da presença da doença.

Quando analisadas a composição, a CCS e a CBT do leite coletado nas propriedades, apesar das falhas de manejo apontadas, as amostras se mantiveram dentro dos critérios estabelecidos pela legislação, à exceção da CBT (Tabela 2).

O valor de CCS médio das propriedades manteve-se $6 \%$ abaixo do limite máximo estabelecido na IN 76. Individualmente, 33 propriedades tiveram contagem dentro do padrão $(61,1 \%)$. A contagem de células somáticas é um indicador de saúde do úbere e revela processos inflamatórios na glândula mamária (ARCURI et al., 2006), sendo considerado uma medida indireta do percentual de quartos mamários afetados pela mastite (SANTOS, 2006). A variabilidade da CCS individual das vacas é muito grande, no entanto, a medida é indicativa de qualidade geral do leite e aceita internacionalmente como padrão (LANGONI et al., 2011).

A CBT média das amostras de leite coletadas esteva acima do permitido pela legislação, em níveis superiores a 6 vezes o limite máximo, revelando que existem falhas na obtenção e conservação do leite nas UPLs da região. Metade delas, (27)

Tabela 2 - Características físico-químicas e microbiológicas médias do leite coletado nas propriedades, relacionados aos padrões estabelecidos pela IN 76 (BRASIL, 2018)

\begin{tabular}{ccc}
\hline Parâmetros & Valores médios & Valores estipulados pela IN 76 \\
\hline CCS & $4,7 \times 10^{5} \mathrm{CS} / \mathrm{mL}$ & máx. $5,0 \times 10^{5} \mathrm{CS} / \mathrm{mL}$ \\
CBT & $2,0 \times 10^{6} \mathrm{UFC} / \mathrm{mL}$ & máx. $3,0 \times 10^{5} \mathrm{UFC} / \mathrm{mL}$ \\
Gordura & $4,12 \mathrm{~g} / 100 \mathrm{~g}$ & mín. $3,0 \mathrm{~g} / 100 \mathrm{~g}$ \\
Lactose & $4,46 \mathrm{~g} / 100 \mathrm{~g}$ & mín. $4,3 \mathrm{~g} / 100 \mathrm{~g}$ \\
Proteínas & $3,26 \mathrm{~g} / 100 \mathrm{~g}$ & mín. $2,9 \mathrm{~g} / 100 \mathrm{~g}$ \\
Sólidos totais & $12,62 \mathrm{~g} / 100 \mathrm{~g}$ & mín. $11,4 \mathrm{~g} / 100 \mathrm{~g}$ \\
\hline
\end{tabular}


estavam dentro dos padrões estabelecidos pela Instrução Normativa no que se refere a CBT. Segundo Taffarel et al. (2015) uma alta CBT pode estar relacionada à falta de higiene durante a ordenha juntamente com a falha no resfriamento do leite que é um dos pontos chaves para manter o padrão microbiológico após a ordenha. A maioria das propriedades analisadas realiza o resfriamento do leite com tanques de imersão. Os tanques de imersão possuem as temperaturas muito variáveis e são dependentes do ambiente e da manutenção da temperatura da água na hora de colocar novos latões de leite. A IN 76 estabelece que o leite deve ser mantido em refrigeração até $4{ }^{\circ} \mathrm{C}$, e transportado aos estabelecimentos de leite e derivados, atendendo ao limite máximo de $7{ }^{\circ} \mathrm{C}$, verificados na recepção do leite no estabelecimento.

Motta et al. (2015) encontraram resultados dos principais constituintes do leite de vaca (gordura, lactose, proteínas e sólidos totais) semelhantes aos verificados nesta pesquisa, em estudo com leite informal na região sudeste do estado de São Paulo. Os teores de gordura e proteínas médios se mantiveram acima dos estabelecidos pela legislação, o que, segundo Santos (2006), pode ocorrer devido à concentração proveniente da redução na produção de leite. Quando o animal está com mastite os constituintes do leite podem variar positivamente ou negativamente, assim como também ocorre devido a influência da dieta oferecida aos animais, sazonalidade e características raciais (GONZALEZ et al., 2004).

\section{CONCLUSÕES}

A produção de leite nas UPLs estudadas é realizada concomitantemente com outras atividades agropecuárias, com baixa tecnificação e especialização. A produção de leite média por vaca se encontra acima da média nacional, porém, abaixo da média estadual. A qualidade do leite mostrouse insatisfatória devido ao alto índice de contagem bacteriana, a qual encontra-se no nível de 6 vezes o limite máximo estabelecido pela IN 76. Este resultado pode ser atribuído à falta de ações de boas práticas de manejo de ordenha, higienização de utensílios e equipamentos, bem como conservação do leite nas propriedades.

\section{REFERÊNCIAS}

ARCURI, E. F et al. Qualidade microbiológica do leite refrigerado nas fazendas. Arquivo Brasileiro de Medicina Veterinaria e Zootecnia, v. 58, n. 3, p. 440-446, 2006.

BOZO, G. A. et al. Adequação da contagem de células somáticas e da contagem bacteriana total em leite cru refrigerado aos parâmetros da legislação. Arquivo Brasileiro de Medicina Veterinária e Zootecnia, v. 65, n. 2, p. 589594, 2013.

BRASIL. Ministério da Agricultura, Pecuária e Abastecimento. Instrução Normativa $n^{\circ} 76$, de 26 de novembro de 2018. Regulamentos Técnicos que fixam a identidade e as características de qualidade que devem apresentar o leite cru refrigerado, o leite pasteurizado e o leite pasteurizado tipo A. Diário Oficial da União: seção 1, Brasília, DF, n. 230, p. 9, 30 nov. 2018.

DINGWELL, R. T. et al. Association of cow and quarter-level factors at drying-off with new intramammary infections during the dry period. Preventive Veterinary Medicine, v. 63 , n. 1-2, p. 75-89, 2004.

FERNANDES, L. A. O.; WOODHOUSE, P. J. Family farm sustainability in southern Brazil: An application of agri-environmental indicators. Ecological Economics, v. 66, n. 2, p. 243-257, 2008. 
GONZALEZ, H. L. et al. Avaliação da qualidade do leite na bacia leiteira de pelotas, RS. efeito dos meses do ano. Revista Brasileira de Zootecnia, v. 33, n. 6, p. 1531-1543, 2004.

H A G N E S T A M - N I E L S E N, C.; ØSTERGAARD, S. Economic impact of clinical mastitis in a dairy herd assessed by stochastic simulation using different methods to model yield losses. Animal, v. 3, n. 2, p. 315-328, 2009.

HOGEVEEN, H.; HUIJPS, K.; LAM, T. Economic aspects of mastitis: New developments. New Zealand Veterinary Journal, v. 59, n. 1, p. 16-23, 2011.

IBGE - INSTITUTO BRASILEIRO DE GEOGRAFIA E ESTATÍSTICA. Produção da Pecuária Municipal 2017, Rio de Janeiro, v. 45, p.1-8, 2017. Disponível em: https://biblioteca.ibge.gov.br/visualizacao/ periodicos/84/ppm_2017_v45_br_ informativo.pdf Acesso em: 20 mar. 2019.

INCRA - INSTITUTO NACIONAL DE COLONIZAÇÃO E REFORMA AGRÁRIA. Tabela com módulo fiscal dos municípios. 2013. Disponível em: http://www.incra.gov.br/ sites/default/files/uploads/estrutura-fundiaria/ regularizacao-fundiaria/indices-cadastrais/ indices_basicos_2013_por_municipio.pdf/ Acesso em: 19 mar. 2019.

LANGONI, H. et al. Aspectos microbiológicos e de qualidade do leite bovino. Pesquisa Veterinária Brasileira, v. 31, n. 12, p. 10591065, 2011.

LOPES, A. D. et al. Características técnicas das propriedades de baixa escala leiteira observadas na área de abrangência do escritório de desenvolvimento rural de Jaboticabal - SP. Revista de Ciência e Extensão, v. 6, n. 2, p. 36-45, 2010.
MAIA, G. B. S. et al. Produção leiteira no Brasil. BNDES Setorial, n. 37, p. 371-398, 2013.

MARTINS, J. M. et al. Boas práticas agropecuárias de fabricação em unidades de leite e derivados. Belo Horizonte: EMATER-MG, 2012. 43 p.

MILINSKI, C. C.; GUEDINE, P. S. M.; VENTURA, C. A. A. O sistema agroindustrial do leite no Brasil: Uma análise sistêmica. In: CONGRESSO BRASILEIRO DE SISTEMAS, 4., 2008, Franca. Anais [...].Franca: Centro Universitário de Franca Uni-FACEF, 2008. Disponível em: http://legacy.unifacef.com. br/quartocbs/artigos/C/C_151.pdf Acesso em: 30 abr. 2017.

MILLOGO, V. et al. Raw milk hygiene at farms, processing units and local markets in Burkina Faso. Food Control, v. 21, n. 7, p. 1070-1074, 2010.

MOLINA, L. R. Diagnóstico, controle e monitoramento da ocorrência de mastite em rebanhos leiteiros. Leite Integral, v. 3, Caderno Especial 4, p. 24-46, 2008.

MOTTA, R. G. et al. Indicadores de qualidade e composição de leite informal comercializado na região sudeste do estado de São Paulo. Pesquisa Veterinária Brasileira, v. 35, n. 5 , p. 417-423, 2015.

PICOLI, T. et al. Nível de instrução de produtores rurais e as características da produção leiteira. Science and Animal Health, v. 2, n. 2, p. 147-159, 2014.

PICOLI, T. et al. Milk production characteristics in Southern Brazil. Semina: Ciências Agrárias, v. 36, n. 3 Supl1, p. 1991, 2015.

PONZILACQUA, B. et al. Influência do pré e pós-dipping sobre a ocorrência de bactérias 
causadoras de mastite em leite de tanques resfriadores. Veterinária e Zootecnia, v. 20, p. 318-319, 2013.

RIES, J. E. Relatório socioeconômico da cadeia produtiva do leite no Rio Grande do Sul: 2017. Porto Alegre: Emater/RS-Ascar, 2017. $64 \mathrm{p}$

ROSA, L. S.; QUEIROZ, M. I. Avaliação da qualidade do leite cru e resfriado mediante a aplicação de princípios do APPCC. Ciência e Tecnologia de Alimentos, v. 27, n. 2, p. 422430, 2007.

SANTOS, M. V. O uso da CCS em diferentes países. In: MESQUITA, A. J.; DURR, J. W.; COELHO, K. O. (Ed.). Perspectivas e avanços da qualidade do leite no Brasil. Goiânia: Editora Talento, 2006. p. 181-197.

SCALCO, A. R.; SOUZA, R. D. C. Qualidade na cadeia de produção de leite: diagnóstico e proposição de melhorias. Organizações Rurais \& Agroindustriais, v. 8, n. 3, p. 368377, 2006.

SCHNEIDER, S. Teoria social, agricultura familiar e pluriatividade social. Revista
Brasileira de Ciências Sociais, v. 18, n. 51 p. 99-121, 2003.

TAFFAREL, L. E. et al. Variação da composição e qualidade do leite em função do volume de produção, período do ano e sistemas de ordenha e de resfriamento. Semina: Ciências Agrárias, v. 36, n. 3, p. 2287-2300, 2015.

TEODORO, V. A. M.; MACHADO, G. M.; MIGUEL, E. M; TEIXEIRA, S. A.; TELLES, S. S.; PEREIRA, D. A. Importância da implementação de boas práticas na produção de leite para a fabricação de queijos artesanais de Minas Gerais. Informe Agropecuário, v. 34, n. 273, p. 17-29, 2013.

VILAR, M. J. et al. Application of ATP bioluminescence for evaluation of surface cleanliness of milking equipment. International Journal of Food Microbiology, v. 125, p. $357-361,2008$.

VILAR, M. J. et al. Implementation of HACCP to control the influence of milking equipment and cooling tank on the milk quality. Trends in Food Science and Technology, v. 23, n. 1, p. 4-12, 2012. 